\title{
7. Digitalised management, control and resistance in platform work: a labour process analysis
}

\author{
Simon Joyce and Mark Stuart
}

\section{INTRODUCTION}

The era of platform work has presented employment researchers with a number of challenges. ${ }^{1}$ In this chapter, we focus on conceptual and theoretical issues; specifically, the problem of how best to understand platform worker contestation and resistance. To do this, we develop an application of labour process theory (Braverman 1974; Edwards 1989, 1990; Hyman 1987; Littler 1982; Thompson 1990). While the control-resistance duality of labour process approaches is fairly familiar in platform work research, to date there has been a significant - indeed, problematic - overemphasis of control, while platform worker resistance has been correspondingly downplayed (for instance, Gandini 2019; Howcroft and Bergvall-Kåreborn 2019; Rosenblat and Stark 2016; Shapiro 2018; Sharma 2020; Veen et al. 2020; Wood et al. 2018). The overemphasis of control in previous research - while in some ways understandable, given the novelty of algorithmic technology - has skewed accounts of platform work's nature and dynamics. In particular, platform worker resistance has been under-researched and under-theorised. This chapter aims to redress the balance.

Despite the widespread focus on control, evidence of platform worker resistance continues to accumulate. Most obviously, there is regular coverage in news media of platform worker strikes, protests, and legal challenges (see below). Some academic and activist researchers have explicitly examined indeed, championed - such resistance (Cant 2020; Tassinari and Maccarrone 2020; Woodcock 2018). Other evidence of platform worker resistance appears in research focussed on control, where it is often assumed to be of little consequence, or easily disarmed by platform control mechanisms (Griesbach et al. 2019; Rosenblat and Stark 2016; Shapiro 2018; Sharma 2020; van Doorn and Badger 2020). Such accounts often reproduce problematic notions of 
control familiar from previous eras; in particular, mirroring heavily criticised 'electronic panopticon' accounts of 1990s ICT systems (for an explicit revival of this analysis, see Woodcock 2020; for a critical review of earlier debates, see Bain and Taylor 2000; Moore and Joyce 2020). Consequently, despite the obvious empirical persistence of platform worker resistance, it appears as something of an anomaly in the absence of any adequate theorisation.

Our argument in this chapter is that labour process theory can provide an explanation for both the nature and dynamics of platform worker resistance, as well as its persistence. To date there has been little systematic effort to apply labour process theory to platform work. Gandini (2019) argues that a labour process approach might be fruitful in this area (see also Moore and Joyce 2020), and Tassinari and Maccarrone (2020) show how labour process analysis can be applied to a detailed case study of food delivery platform workers. We build on these foundations to develop a broader account. In particular, we show how aspects of platform work usually associated with the control of labour are also key sites of platform worker resistance.

The starting point for our analysis is the understanding that platform work establishes a labour-capital relationship between workers and the company running the app (Gandini 2019; Joyce 2020). For labour process theory, capitalist labour processes are characterised by a dual tendency towards both control over the labour process by managers, as well as resistance to that control by workers. As a result, the labour process is a site of inherent conflict and contestation. The digitalised management methods of platform work, we argue, represent an evolution in the systems utilised by managers to control workers at the point of production, but this solution is no more able to resolve the intractability of worker resistance than was any management system that came before it. In consequence, platform management methods do not represent a complete solution to the problems capital faces in managing labour. Rather, and despite their undoubted novelty, platforms represent another example of what Hyman (1987, p. 30) has aptly characterised as 'different routes to partial failure'.

We begin with a discussion of the conceptual framework of labour process theory. Next we set out an understanding of platform work as a set of management methods for organising work and managing a workforce. Subsequently, we apply our labour process analysis to empirical evidence on platform work and platform worker resistance, drawn from own and others' research.

\section{CONTROL AND RESISTANCE IN LABOUR PROCESS THEORY}

Labour process theory (LPT) permits the analysis of work organisation on two levels. First, LPT identifies the underlying dynamics common to all forms 
of paid work under capitalist relations of production: specifically, a dual dynamic of control and resistance. Second, LPT examines specific management methods for organising work and extending control over the labour process; methods which vary historically and across different industries and workplaces, which can be more or less effective from management's point of view, but which can never do away entirely with the underlying dynamics of control and resistance. As we show below, the dual level analysis of LPT is particularly useful for clarifying issues in platform work.

For its understanding of the employment relationship, LPT draws heavily on Marx's account of the exploitation of labour at the point of production viz., that capital seeks to extract surplus labour by ensuring (or attempting to ensure) that workers produce a greater quantity of value than is returned to them in the form of wages. For LPT, as for Marx, this underlying dynamic is present regardless of whether any given capitalist in fact makes any profit. An equivalent dynamic is also present in parts of the economy - such as the public sector - where profits as such are never made (Fine and Saad Filho 2010). Although aspects of the labour process were already studied in fields such as industrial relations and the sociology of work, LPT took off as a more or less coherent research project following the publication of Braverman's (1974) account of the labour process under 'monopoly capital' conditions. Despite Braverman's avowedly Marxist approach, however, during the 1980s LPT explicitly moved away from any commitment to Marxism as a wider theory of society and history, despite retaining a number of its key conceptual insights. Thompson (1990, pp. 99-101) codified the 'core theory' of LPT, based on four main components:

- the labour process is a site of the exploitation of labour

- the logic of accumulation 'forces capital constantly to revolutionise ... production'

- the logic of accumulation leads to a 'control imperative ... [to] regulate the labour process'

- 'the social relation between capital and labour is an antagonistic one' which gives rise to 'a variety of forms of conflict and resistance'.

Thompson claims, though, that this account 'is not in my view Marxist', because it detaches Marx's wider theory of society and history; specifically, the notion of social change through class struggle (ibid., p. 102). Likewise, Edwards (1986) distances his broadly comparable account from Marx on similar grounds, while nevertheless retaining a nearly-Marxist notion of 'structured antagonism' in labour-capital relations based on exploitation, which may or may not be expressed in overt struggle or resistance. 
The key link in LPT analysis is that the drive to extract surplus labour means that capital must achieve some level of control over the labour process, over aspects such as the speed and intensity of labour, quality standards of production, what equipment, tools and raw materials are used, and how. The dynamic to establish control is rooted in a fundamental uncertainty within the capitalist labour process, commonly termed the indeterminacy of labour (Thompson and Smith 2010). Again, this analysis is drawn from Marx: the commodity that workers sell to capitalists (in exchange for a wage) is not labour but the capacity to labour (Edwards 1986), termed 'labour power' by Marx (1976). Workers' capacity to labour is bought by a capitalist, usually for a specified number of hours each day, but it is then up to the capitalist - or, more usually, managers acting on behalf of capital - to ensure that each worker's capacity to labour is transformed into actual concrete labour, of a specific type, standard and intensity (Thompson 1990). That is, for LPT, control means control of the labour process. It is not necessary, from this perspective, for managers to control the hearts and minds, or subjectivity, of workers - even though some managers seem to want that.

Despite - or, perhaps, because of - the centrality of control within the LPT tradition, the concept has been a focus of considerable controversy. Famously, Braverman (1974) saw deskilling ${ }^{2}$ as management's main weapon in a long historical process whereby capital increasingly took control of the labour process from the hands of skilled workers, through a progressive application of Taylorist 'scientific management', including: separating the conception and execution of labour; breaking down complex work into simple routinised tasks; and replacing skilled labour with machinery and semi- or unskilled workers. Despite its huge (and continuing) impact, however, Braverman's account was almost immediately criticised as deterministic and one-dimensional. Critics pointed out that, historically, there was no clear correspondence of deskilling and control. For the 19th century, Samuel (1977) showed that many groups of skilled workers showed little sign of rebellion against capital, and Lazonick (1979) demonstrated that the introduction of machinery by managers was usually driven not by the need to control skilled labour, but by moves to improve and standardise products for rapidly expanding markets. Moreover, there is plenty of evidence from the 20th century that semi- and unskilled (i.e. deskilled) workers could prove extremely resistant to managerial control (for instance, Beynon 1984). Critics of Braverman pointed out that managers in fact use a variety of methods for achieving control over the labour process. Friedman (1977) distinguishes two strategies: 'direct control' and 'responsible autonomy'; while Edwards (1979) identifies three methods: 'simple', 'technical' and 'bureaucratic' control. While Edwards viewed his three methods in terms of a historical evolution, Freidman linked his two strategies to core and peripheral labour markets. 
Although Edwards and Friedman recognise variation in forms of management control, they also retain a problematic structural determinism apparent in Braverman's account (Edwards 1989, 1990, 1992; Hyman 1987; Storey 1985). The theoretical problem, summed up by Storey (1985, p. 194) is that many accounts 'rest on functionalist premises that capital must and can devise coherent systems of control to ensure the structurally necessary extraction of surplus value', resulting in a 'single-track search for definitive and comprehensive modes of work control which are assumed to exist'. The problem with such approaches is that, both historically and theoretically, management methods, systems and practices are fractured, partial and contradictory. Control is rarely - if ever - the central strategic concern of management (Hyman 1987). Even the purchase of new machinery is seldom primarily concerned with the control of labour. Other pressing issues for managers include production schedules, purchasing, marketing, finance, sales, and so on. As Hyman (1987, p. 35, original emphasis) puts it: 'The contradictory role of management as both co-ordinator of a complex and often baffling productive operation, and simultaneously a vehicle of discipline and disruption, is almost inevitably reflected in consequential contradictions both between and within the various managerial specialisms'.

This is not to say that managers are not concerned with labour control; rather, it is to emphasise that management cannot be treated as the undifferentiated 'self-conscious agent of capitalist compulsion to subordinate labour' (Hyman 1987, p. 34). Contradictory tendencies within the management function form the irreducible setting for management strategies for control of the labour process. As a result of these contending pressures, managerial strategies rarely mesh together neatly. These structural constraints undermine management strategies - including strategies for control - reducing them, as Hyman (ibid., p. 30) puts it, to 'different routes to partial failure'.

The second level of analysis in LPT examines particular, concrete management methods for controlling the labour process. One of the great strengths of LPT research is the large quantity of empirical research accumulated over some four decades, mostly in the form of detailed case studies. Problems arise, though, if the two levels of analysis are conflated; in particular, by the assumption that management methods intended to control the labour process are straightforwardly able to do so. Theoretically, such an assumption abolishes the underlying dynamics within the labour process, as well as contradictions within management. The theoretical challenge, then, is to maintain an understanding of both the underlying dynamic of control and resistance, as well as the variety and specificity of management practice, including methods of control. To this end, Edwards (1990, p. 145) distinguishes between general control, at the level of 'the overall effectiveness of the production system', and detailed control, at the level of the immediate labour process. Similarly, Storey 
(1985, p. 198, original emphasis) poses the problem in terms of "levels" and "circuits" of control' in which there exits 'a variety of means of control'. While it is not possible fully to explore these rich debates within the confines of this chapter, the key point is that adequate analysis of the labour process must examine the specificity of management methods, while retaining an understanding of the contradictions of management, the variety of management methods and the necessarily partial nature of systems of managerial control.

Often, however, evolving forms of management methods are heralded as entirely new and revolutionary, as if they have resolved previous difficulties once and for all (Edwards 2007). Littler (1982, p. 5) terms this the 'panacea fallacy', which repeatedly claims to have identified 'the magic strategy that successfully stabilised capital-labour relations'. It is not surprising that corporate and managerialist narratives promote such claims. It is important, though, that platform work research avoids the temptations of the panacea fallacy; for instance, by assuming that claims made about the technical capacities of platform technology actually describe the labour processes of platform work and the experience of platform workers. As discussed below, many aspects of platform work are not new at all; furthermore, others are significantly less monolithic than is often assumed.

For LPT, control - however partial and contradictory - is not the end of the story. The drive to control brings with it a corollary: the drive to resist. That is, LPT identifies a dual dynamic within the capitalist labour process, which entails both control and resistance. As a result, all management strategies for control face not only the challenge of contradictions within the management function, but also the intractability of worker resistance (Ackroyd and Thompson 1999). Importantly, LPT sees the drive to resist as an underlying dynamic which may or may not result in actual resistance. Moreover, where resistance does emerge, its nature and outcome are not predetermined. Resistance may be collective or individual, large or small, organised or unorganised, effective or ineffective. But it is seldom absent.

Despite the centrality of resistance to the labour process framework, theoretical discussion of this key concept is undeveloped by comparison to control. For some accounts, resistance may be largely symbolic (see Ackroyd and Thompson 1999), or may even end up reinforcing control mechanisms; although this latter approach has been hotly disputed (Thompson and Smith 2010). Often, especially in the debates following Braverman, resistance was treated more or less as a constant, assumed presence, which management control methods are designed to overcome. In these accounts, 'workers come to the factory gates as the bearers of a universal recalcitrance to capitalist authority' (Littler 1982, p. 27). What is missing from such accounts is an understanding of the specific ways that the experience of paid work is itself central to generating worker resistance. Hyman (1975) provides a general reminder 
that the labour-capital relationship - including management methods, is a generator of disruption and conflict. Labour process theory provides theoretical means to go beyond this (essential) insight, to analyse specific forms of worker resistance as responses to evolving methods of managerial control. Edwards (1989, p. 188) identifies an 'informal' level of worker resistance, drawing on the work of Mars (1982) and Ditton (1977) examining work 'fiddles'; that is, common practices of rule-breaking by workers, ranging from petty short-cuts to outright criminal activity, intended to shift the balance of effort and reward (see also Ackroyd and Thompson 1999). Edwards highlights the role of informal work groups in devising and perpetuating such practices, some of which may be known about and even encouraged by managers seeking to smooth production. Edwards (1989) also recognises more formal collective resistance such as strikes and other unionised activity (see also Edwards 1992, 2007). Applying a similar approach, Moore and Joyce (2020) distinguish 'grassroots' and 'trade union led' resistance among platform workers. Despite these discussions, frameworks for grasping resistance remain underdeveloped.

In a celebrated intervention, Burawoy (1979) argued that a simple dichotomous framework of control versus resistance is inadequate, and added the notion of consent to capture the non-conflictual effort of workers in a Chicago engineering factory. This contribution has been much debated. Clawson and Fantasia (1983, p. 671) argue that Burawoy downplays the reality of worker contestation and resistance by presenting an undialectical analysis in which 'all social processes benefit the capitalist class'. Furthermore, Edwards (2007) points to the fundamental problem of excessive generalisation from one case study. Despite these problems, Burawoy's influence has been considerable.

Burawoy is important in the context of platform work because studies that focus on its algorithms often overstate the extent to which platform technology ensures compliance with, or even internalisation of, platform company priorities and rationalities (for instance, Ajunwa and Greene 2019; Griesbach et al. 2019; Wu et al. 2019). Aside from theoretical difficulties, the empirical problem with the over-enthusiastic use of control and consent in platform work research is the sheer scale of non-consent and non-control evident in a growing number of studies, as well as in news media reporting. In reality platform work is the location of globally significant levels of worker organisation, protest and resistance, often of a very militant type (Joyce et al. 2020). While Burawoy's 'consent' may be useful in some contexts, it is far from clear that it is universally applicable, especially in platform work.

Consequently, we retain the classic control-resistance approach developed in accounts such as Thompson (1990; also Thompson and Smith 2010) and Edwards (1986, 1990). Most importantly, we wish to emphasise the dual nature of the underlying dynamic within the capitalist labour process, comprising both control and resistance. Accounts that see only one side of this duality 
are, at best, limited. As we show below, platform management methods offer managers opportunities for enhanced control of the labour process, while at the same time providing sites for platform worker resistance and contestation.

PLATFORM WORK AS MANAGEMENT METHOD

Platforms and platform work have been defined in various ways. For some, platforms are a technical arrangement of computer hardware, software and processing power (Kenney and Zysman 2016). For others, platforms represent novel economic formations, based on processing data as a raw material (Srnicek 2016), or new ways of engaging a workforce (Vallas and Schor 2020). Some focus on the role of platforms as intermediaries for economic transactions (Agrawal et al. 2013; Ajunwa and Greene 2019; Bergvall-Kåreborn and Howcroft 2014; Hall et al. 2019; Hall and Krueger 2018; Horton and Zeckhauser 2016; Schmidt 2017), sometimes distinguishing between 'capital platforms' mediating the sale or rent of goods and services, and 'labour platforms' mediating paid work (Farrell and Greig 2016). Others, though, point to the highly active role of platforms in shaping markets, including labour markets, as evidence that a passive 'mediator' definition is problematic (Forde et al. 2017). Further definitions highlight what are seen as the novel social relations of platforms, in the 'triangular' relationship of worker-platformcustomer (Calo and Rosenblat 2017; Harris and Krueger 2015; Lehdonvirta et al. 2019; Schörpf et al. 2017). When it comes to platform work, perhaps a common shared definition might be, 'paid work mediated by and online platform' (Forde et al. 2017).

These definitions all capture certain aspects of platform work. For present purposes, however, we would emphasise its character as a management system. Regardless of definition, the companies that run platforms are rapidly innovating and refining a new fusion of methods for organising work and managing workers. Some elements of this fusion are recent developments; most obviously, the digital technology of apps and algorithms. Other elements are much older: for instance, work carried out as-and-when required; payment by piecework; worker-provided equipment; 'triangular relationship between the producer, the end-user and the intermediary' (Stanford 2017, p. 384) the latter being strongly similar to putting-out systems found in the earliest period of industrialisation (see Leung et al., this volume). Moreover, the fusion of management methods developing within platform work are already disseminating far more widely. For instance, in the application of algorithmic distribution and monitoring of work, in settings where the standard model of employment is still firmly in place (Moore and Joyce 2020). 
In this sense, platform work represents an evolution of management methods, in the same way that previous systems emerged, such as Taylorism, human resource management or lean production. In adopting this approach, we understand platform work as a portfolio of methods that managers can use for organising and managing a workforce. Here, we follow Moore and Joyce (2020), who see platform management methods as a composite of technological and organisational forms that managers can deploy, in various combinations, in order to organise work and manage workers, and to exercise a degree of control over the labour process. Moore and Joyce (ibid., p. 5) identify a number of management methods within the platform model, including:

- algorithmic allocation of work

- digital tracking and monitoring of workers

- integration of customer ratings into performance management systems

- setting of prices for services provided and rates of pay for work conducted

- extraction of commission on every transaction

- engagement of workers on self-employed or independent contractor status

- legal and regulatory arbitrage ${ }^{3}$ concerning worker status and service provision.

Platforms that mediate paid work tend to use most of these methods, but it is not necessary that they use them all. Platform companies adopt different business models, with variation in how labour is managed. For instance, platforms such as Amazon Mechanical Turk and Upwork allow users to set prices, whereas platforms such as Uber set all the terms of each transaction. Similarly, some platforms - for instance, Upwork - allow customers to monitor workers, while others monitor workers directly via GPS tracking, etc. It is not even the case that platform workers are always engaged on a self-employed basis; for instance, prior to its withdrawal from the market, Foodora riders in Germany were legally employees, as the company took advantage of 'mini-job' regulations (Ivanova et al. 2018). Elsewhere, court rulings and changing legal frameworks are leading to shifts in the employment status of platform workers away from self-employment (see below). One advantage of a multi-strand approach to conceptualising platform work is that it can encompass change and variation as platform work evolves. Conceptualising platform work in this way also avoids the problem of 'monism' identified by Storey (1985, p. 207) - that is, 'the tendency for commentators to seek definitive singular types of control'. For the approach proposed here, platform work is one option available for capitalist firms: alternatives include Taylorism, lean production and HRM, as well as partial adoption of these models, hybrids and other firm-level variations.

Conceptualising platform work as a system for managing labour also informs the development of labour process analysis, and in doing so highlights 
the dynamic relations between methods of control and patterns of worker resistance. The platform menu of platform management methods listed above fall into three main groups: algorithmic management (allocation of work, digital tracking and monitoring, integration of customer ratings); pay (setting of prices and rates of pay, extraction of commission); and wider forms of regulation (self-employed or independent contractor, legal and regulatory arbitrage). Each of these methods carries specific implications for control of the labour process. In the next section, we set out evidence to show that these broad dimensions of platform management control also generate and shape emergent platform worker resistance.

\section{CONTROL AND RESISTANCE IN PLATFORM WORK}

In this section, we apply the labour process framework outlined above to show how platform management methods shape emerging patterns of platform worker resistance. Theoretically, the important point is that methods of control and patterns of resistance are linked via the dual control-resistance dynamic within capitalist labour processes. In other words, platform methods do not simply impose control; they are also key drivers of platform worker resistance. Our argument returns to Hyman's insistence that capitalist management, because of its exploitative nature, is a principal source of conflict and contestation. In addition to this first level of analysis in terms of underlying dynamics, we are also able to add second level analysis of specific forms and categories of platform worker resistance, linked to specific aspects of platform management methods. The section therefore follows the three broad categories of platform management methods outlined above - algorithmic management, pay, broader regulatory issues - and, for each, outlines aspects of management control and empirical evidence of platform worker resistance.

\subsection{Algorithmic Management}

The obvious place to start any discussion of control and resistance in platform work is with algorithms and their surrounding technology. Algorithm-related issues around the allocation of work, digital tracking and monitoring of workers, and ratings systems have featured heavily in platform work research. This research effort has identified important aspects of the functioning of the platforms of platform work. However, these features have been seen almost exclusively in terms of control. As a result, the extent to which platform algorithms are malleable and open to challenge and modification has been downplayed, leading to a one-sided understanding of the extent to which platforms have succeeded in resolving the inherent indeterminacy of labour. 
Several important aspects of algorithms are directly related to management efforts to control the labour process. Most obviously, algorithms are central to the allocation of work and, often, to monitoring its completion. Early research on platform work identified the integration of customer ratings into algorithmic performance management systems as an often harsh and non-transparent mechanism for allocating work (Berg 2016; Bergvall-Kåreborn and Howcroft 2014; Chen et al. 2015; De Stefano 2015; Irani 2015; Rosenblat and Stark 2016). If ratings slipped below a certain level, workers would lose access to the best-paying jobs, or would even be barred from the platform altogether: 'deactivation', as it became known (De Stefano 2015). Consequently, pressure to maintain high ratings becomes a constant but unpredictable disciplining force standing over many platform workers. Research has shown that this pressure can and does result in workers putting up with abusive or discriminatory language from customers, threatening or violent behaviour, criminal activity and even sexual assault, for fear that speaking out or self-defence may result in lower ratings and consequent loss of earnings (Huws et al. 2017; Moore 2018; Raval and Dourish 2016). The fact that ratings cannot be transferred between platforms means that workers become tied to the site where they have built up a good reputation (Kokkodis and Ipeirotis 2016).

Algorithms can also be set to adjust rates of pay according to fluctuating demand for labour, in the infamous 'surge-pricing' systems of Uber and other transportation companies. As anyone who has talked to experienced app-based drivers or riders will testify, different platforms manage 'surge' conditions by different methods, and many of these change with bewildering speed, often un-announced, leading to unexpected fluctuations in earnings more importantly, usually only in a downward direction (Berg and Johnston 2019; Sharma 2020). On many platforms, algorithms not only direct jobs to particular workers, and monitor their completion, but also keep track of any work refused, which can also lead to deactivation (Raval and Dourish 2016; Ravenelle 2017; Rosenblat and Stark 2016). Some apps track worker locations, as they drive or ride around a city. While some have termed these algorithmic prompts 'gamification' (Woodcock and Johnson 2018), in reality, changing rates of pay to get more effort from workers, or threatening them with loss of work and earnings, are well-established employment practices, which represent the direct continuation of very old-school methods for labour management and control. On these platforms, work is not becoming more like a game; it is becoming more like a job.

What is striking, but seldom discussed, about even these most algorithmic of management methods, is evidence that platforms have neither been able to overcome the underlying dynamic of worker resistance nor eliminate worker contestation in practice. At an individual level, Attwood-Charles (2019) has shown that couriers can avoid platform rules with little consequence. (Wood 
et al. 2018) have shown that digital freelancers are able to avoid surveillance of their work by the platform. Taxi-app drivers use online forums to exchange information about changes to platform algorithms, as well as tips on how to avoid getting caught breaking platform rules (Rosenblat and Stark 2016). Online clickworkers use forums to exchange information about the platform, and to warn each other about customers who pay poorly or not at all (Irani and Silberman 2013). Food delivery riders gather in town squares or outside restaurants and exchange information about algorithmic changes and ways of maximising income, and how best to deal with problems with the platform (Cant 2020). Although these types of everyday resistance ${ }^{4}$ have begun to feature more often in research, it seems clear that much remains to be discovered and investigated.

A further feature of platform work is that algorithms change in response to external pressures, including driver/rider shortages, increased orders, or bad weather. Over time, workers learn how to take advantage of this. Research shows that platform workers, for instance grocery delivery drivers on Instacart in the US, have learned that rejecting low-paying jobs will train the algorithm to channel higher-paying jobs. One worker commented: 'I feel like I trained the computer what I'll do. Eventually that computer knows I'm not going to take all kinds of $\$ 10$ orders. So they stop sending them to me and they send me more decent stuff' (Griesbach et al. 2019, p. 6).

What is more, these workers had collectivised these tactics for training the algorithm via online social media groups. Another reported that if workers refused to accept low-paying orders: 'the system starts to learn that that's not going to work because then that makes the orders late and we have unhappy customers' (ibid., p. 6).

Effectively, these workers have reinvented the age-old practice of output restriction, a well-known tactic for increasing pay rates under piecework systems, recognised by Taylor as 'soldiering' (Braverman 1974). Instead of bargaining with a foreman, however, these workers were training an algorithm, in an elementary form of pay bargaining. In a similar approach, we have interviewed clickworkers who combined collectively to manipulate algorithmic preference settings in order to secure increased rates of pay. It is also well-established that experienced clickworkers use software patches and browser extensions to increase access to better-paying tasks, and that these are effectively collectivised through online forums (Irani and Silberman 2013; Salehi et al. 2015). Taking a more straightforwardly technical approach, Chen (2018) reports Didi drivers in China using additional code with the algorithm, so that they could reject low-paying jobs without the app realising. In our own research, we have encountered two groups of delivery riders who were attempting to reverse-engineer apps in order to gain a clearer understanding of their operation. Veen et al. (2020, p. 400) found food delivery workers 
engaged in 'manipulation of geo-spatial data, theft of food ... and evasion of shift work'. Other research reports delivery riders: using software to interfere with the app to hide GPS tracking data; using coordinated data-requests under Europe's GDPR data protection regulations to interfere with the platform company's use of data, and to restrict deactivations; and combining multiple data-requests in legal challenges to platforms' use of data (van Doorn and Badger 2020, pp. 11-13).

The point of these examples is not to claim that workers have overcome, or are on the verge of overcoming, the technical capacities of platform algorithms. These examples are important for two reasons. First, they demonstrate the continuing relevance of the 'panacea fallacy' (Littler 1982, p. 5). There are many previous examples of new systems of work technology being introduced, with accompanying predictions that worker organisation and resistance would be eliminated as a result. The best-known example is the introduction of the moving production line in auto factories in the first decades of the 20th century, which was widely expected to provide the panacea for management efforts to control union organisation (Edwards 1979). Such expectations now look faintly ridiculous, given the history of worker militancy in auto plants. The process of workers figuring out the new technology, learning where the pressure-points are, what tactics work and what don't, what forms of organisation are most appropriate, these processes take time; commonly, around 25 years (Moody 2018). We would therefore expect worker resistance to algorithmic management to develop over a period of years and the emergent evidence represents the early development of such a process. While the problems of extrapolating a trend into the future are well known, this expectation seems less unlikely than the repeatedly mistaken claim that a panacea has this time been discovered. Indeed, if anything, platform workers are ahead of the curve.

The second reason why these examples are important is that they have emerged from research that is, generally, not looking for worker resistance, not expecting to find any, and often dismissive of its significance. We would argue that this reticence on the part of platform work research often reflects an incautious approach to dealing with claims made on behalf of algorithmic technology. It is in accounts of its digital technology that platform work research comes closest to expressing a version of the 'panacea fallacy'. Certainly, platform companies and Silicon Valley publicists have made such claims very loudly over recent years; so much so that even the Financial Times headlined its review of Uber's valuation as 'mythbusting' (Kaminska 2016). Algorithmically focused research commonly discusses 'control' in platform work, but resistance is addressed much more rarely. A key benefit of the labour process approach is that it sensitises research to the dual dynamic of control and resistance, and places worker resistance much higher up in the list of research questions. 


\subsection{Pay}

Pay is a central aspect of platform management methods, and one that has been much commented on but little researched. This is surprising, given that pay has long been recognised a fundamentally important aspect of control in management of the labour process (for an exception, see Wu et al. 2019). Very commonly, platform work involves some version of piecework. The range of piecework systems in platform work is great. At one end of the scale, 'clickworkers' on platforms such as Amazon Mechanical Turk or Microworker can earn as little as two cents per microtask, and overall earnings - such as they are - are made up from many such small and brief tasks (Berg 2016; Berg and Rani 2018). Elsewhere, drivers on ride-hailing apps are paid per trip, in much the same way that taxi-drivers have been paid for many decades previously. Similarly, freelance-type platform work is still paid by the project, in fairly recognisable continuity with non- or pre-platform freelance work (Florisson and Mandl 2018). Other work, such as cooked meal delivery, was established prior to the advent of platforms, but is now far more widespread, and, again, payment is per delivery.

Much of the literature on platform work views piecework as a pernicious and distinctive feature of platform work, especially in accounts that emphasise its 'gig' aspect. Certainly, piecework has often, though not always, been associated with the 'sweated trades' and the bottom end of the labour market (Webb and Webb 1902). For Marx (1976, pp. 692-700), piecework was the payment system most aligned to capitalist relations of production. Historically, however, piecework has a more varied record, and has been used almost interchangeably with time-based payment systems, according to the changing requirements of employers. The reason for this is that piecework and time-based systems are not as different as is often assumed. As noted by Schloss (1898, p. 13) more than 120 years ago:

in the practice of industry, whether a man [sic.] be employed on a time-wage or on a piece-wage, both the time occupied and the work done are, as a rule, taken into account. To put it roughly, time-wage very often has a piece-basis, and piece-wage has in practically all cases a time-basis.

The irreducible link between worker output and time in all payment systems applies no less in the case of platform work: microtasks, which take moments to complete, are paid in cents; taxi-app trips take longer and cost a little less than non-app taxi rides (and journeys that take longer are paid more); freelance projects that last for several days are priced considerably higher. In these cases and others, platform piecework rates clearly entail some calculation as to the time each takes to complete. The low rates of pay for many types of platform 
work, compared with their non-platform equivalents, is less to do with the piecework system as such - which also applies in non-platform settings - and more to do with the greatly increased competition between workers that platforms have enabled, and evasion of regulations controlling service charges and/or pay (see below).

For managers, the obvious appeal of piecework is that it encourages effort. While some see piecework as encouraging workers to 'internalise' the priorities of the platform (Woodcock 2020), in fact the opposite is the case: with piecework, it doesn't matter at all how much a worker identifies with the platform (or any other company) because the same economic compulsion applies to all workers (cf. Marx 1976, p. 899, et passim). As a study of dockworkers in 1970s London put it, in a description of piecework that could apply equally to Deliveroo riders cycling the streets of any city, 'payment systems that rewarded physical effort could be applied, because the pace of work was operator-controlled and not dependent on machines' (Hill 1976, p. 118). Research on platform work shows the same mechanism in operation time and time again. Platform workers continually calculate how many deliveries they need to make in an hour, or how many passenger trips, to achieve a certain level of earnings, or how many hours they need to work per shift to hit their daily earnings target (Aslam and Woodcock 2020; Wu et al. 2019). On food delivery platforms, or taxi-apps, workers often complain about changes to the app, or about non-transparent decisions by the platform algorithms. But what is striking in even the most algorithmically focused research, is that worker complaints over changes to the algorithm very often centre around the impact on pay (Rosenblat and Stark 2016). Workers complain that the app changed and now they are earning less.

As a result, piecework not only contributes towards control: it is also a significant trigger of worker resistance. As the study of London dockers cited above put it, 'piecework also creates numerous occasions for conflict' (Hill 1976, p. 110). Indeed, where workers are sufficiently well organised, managers have abandoned piecework altogether, in order to regain control over the labour process (Brown 1962). Research also suggests that payment-by-results systems in general have a tendency to undermine worker commitment, to breach the 'psychological contract', and to undermine the link between effort and reward, precisely because of widespread perceptions of unfair decision-making. Examples of platform workers complaining of unfair changes to pay are common. One of the most well-known involves the US grocery-delivery app Instacart, where management reset algorithms to include tips in the total pay calculation for each delivery, thereby effectively keeping the tip and deducting it from payment instead of the worker receiving it in addition to payment. In this case, when workers noticed the change, they took screenshots of pay details, posted them to social media websites, and notified 
sympathetic journalists and labour advocates (Captain 2019; for similar events at other delivery platforms, see Ghaffary 2019; Griesbach et al. 2019). As a result of using these tactics over a campaign lasting several weeks, the platform company adjusted its payments upwards. Although the workers did not win all they had hoped for, real changes were forced on the platform, under pressure of public shaming, in what might be the world's first case of collective bargaining by social media. Indeed, the use by workers of screenshots in their challenges to platforms - whether collective public campaigns or individual queries over missing pay - seems to be relatively commonplace. We have interviewed food delivery workers who say they 'screenshot everything' in case payments are less than expected or there are other instances of perceived unfair treatment. This tactic of worker protest reflects a peculiar aspect of algorithmic control in platform work: everything is written down. Or, at least, a great deal is written down. This stands in sharp contrast to many jobs at the lower end of the labour market, where proving what a manager said or did is a fundamental problem for many worker grievances - where, consequently, we might say that informational imbalances are in some respects even greater than in platform work (Cruz et al. 2017).

As these examples illustrate, and contrary to much commentary on platform work monitoring and 'quantification', the fundamental problem for piecework systems is not how to quantify output. The real difficulty is how output is linked to earnings. This calculation - usually made by managers - is always subjective, and always potentially open to contestation (Burchill 1976). A central and recurring site of worker contestation and resistance within piecework systems, therefore, arises every time pay rates are recalculated. As research has shown, on some platforms this happens very often, and usually with no explanation. It is not surprising, then, that worker complaints over rates and levels of pay figure highly in a great deal of platform work research. Often, researchers focus on the algorithm as the source of the grievance. We would suggest that pay is more likely to be the main issue.

Problems relating to pay are becoming increasingly apparent in platform worker resistance. In some cases, worker grievances over perceived imbalances between effort and reward lead to worker resistance of the 'fiddles' variety (discussed above). To date, practices of this type barely register in academic research. Yet, examples uncovered by online news media investigation include survey findings that around one-third of food delivery workers report eating some of the food they were delivering (Gilbert 2019), and the practice of platform delivery workers offering their platform job for hire to other workers on a short-term basis, coordinated via social media sites (McCulloch 2019). Examples from our own research include logging on using a friend's account while suspended, and registering with a food delivery app as a bicycle rider but 
using a car while working. In the case of job renting, some degree of informal collective organisation is clearly present.

Other research suggests that pay is by some distance the leading cause of conflict and resistance by platform workers. Working from databases of global online news reporting, the Leeds Index of Platform Labour Protest has documented a global total of 527 worker protest events involving workers on food delivery platforms, across 18 platforms and 36 countries, between January 2017 and May 2020. The evidence suggests that grievances over pay were an issue in almost two-thirds (63.4 per cent) of these protests across all continents, and accounted for over half of all platform-worker strikes and log-offs (Joyce et al. 2020). Clearly, protests of these types are more organised and public in nature than the fiddles noted above. Nevertheless, the Leeds Index research has found varying degrees of formalisation. Some protests involve union organisation - sometimes traditional unions, sometimes more radical grassroots organisations - while others are based on completely informal work groups (cf. Edwards 1989). Case study evidence from various types of platform work also supports the view of pay as a significant cause of platform worker grievances (Cant and Woodcock 2020; Chen 2018). To date, however, research in this area, as in other aspects of platform worker resistance, remains undeveloped.

\subsection{Wider Regulatory Issues}

Finally, legal and regulatory aspects of platform management methods - in particular, self-employed or independent contractor status workforce, and legal and regulatory arbitrage more generally - form aspects of platform business models that offer direct cost-savings to platform companies, as well as enhanced opportunities for control over the labour process. The classification of platforms workers as self-employed brings immediate financial benefits in the form of direct cost savings. For instance, in the European Union, companies engaging a workforce on self-employed terms save the equivalent of around 25 per cent of their wages bill, by avoiding social security payments and other labour taxes, including paid vacations and entitlements for maternity leave. Moreover, in most jurisdictions, minimum wage regulations do not apply to self-employed workers. This well-established platform strategy, of placing themselves outside normal business regulations, has been termed 'legal and regulatory arbitrage', and in the case of Uber has even been described as the ride-hailing platform's main business advantage over competitor transport companies (Calo and Rosenblat 2017; Fleischer 2010; Kaminska 2016). For Uber, this strategy has centred on efforts to have itself regulated as a technology company, rather than as a transportation provider (Borkholder et al. 2018).

In terms of labour process theory, the avoidance of standard business regulation provides platforms with several advantages. Most obviously, in many 
countries the lack of legal employee status means that platform workers are deprived of important employment and social protections, leaving them more reliant on the platform that provides their income, while removing rights to organise, to bargain and even to be heard (Cherry and Aloisi 2016; Forde et al. 2017; Johnston and Land-Kazlauskas 2018). As a result, worker capacities to resist control over the labour process are reduced. In addition, avoidance of taxi regulations has allowed taxi-app companies to avoid licencing requirements in some locations, to greatly increase driver numbers, and to leverage the resulting oversupply of labour to undermine worker opposition to labour practices, changes to the app, increased commission charges, and so on.

Nevertheless, the legal and regulatory aspects of platform management control methods have also been the sites of considerable worker resistance. In particular, challenges to the classification of platform workers as self-employed have become commonplace in many jurisdictions. Evidence from the Leeds Index (Joyce et al. 2020) suggests that such challenges tend to be concentrated in parts of the globe where the standard model of employment is more common; that is, largely but not exclusively in the global North. The reasons for this are obvious. There is both the legal means to challenge platform companies over worker classification, and the benefits of doing so are greater in countries with more developed employment and social protections. Legal challenges have been brought by individual workers, by established trade unions, by radical grassroots unions and even by platform customers (Cherry 2016; Joyce et al. 2020). As a result, platform companies have been required to treat workers as employees (or are under legal pressure to do so), or else workers have won some sort of 'intermediate' legal status between employment and self-employment, which nevertheless results in greater security or employment and/or increased access to social protections such as paid leave of minimum wage regulations (Forde et al. 2017). Perhaps most notably, efforts by California courts and legislature to reclassify platform workers as employees has led to a lengthy struggle in which platform worker unions have been active participants. The passage of Assembly Bill 5 and the campaign by platform companies, first, to resist its provisions and then - in a \$200 million campaign - to overturn it completely, has yet to reach a final conclusion (Conger 2020; Park 2021). Moreover, it seems unlikely that California's initiative will be the last such episode.

Elsewhere, authorities have moved to re-regulate taxi-app platforms as transport companies. The European Court of Justice has ruled that Uber must be regulated as a transportation company not a tech firm (Khan and Ram 2017). In London - one of Uber's few profitable markets - Uber temporarily lost its licence to operate following a series of scandals involving failure to report criminal activities or to properly vet drivers (Bradshaw 2019). New York has implemented a cap on licence numbers and moved to extend 
minimum hourly wage regulation to include taxi-app drivers - linked to occupancy rates - in an attempt to reduce congestion as well as to improve driver incomes both for taxi-app drivers and for yellow cab drivers, after a tragic series of driver suicides (Berg and Johnston 2019). As a result of this re-regulation, driver earnings have increased, drivers are more secure and platform management prerogatives are restricted (Parrott and Reich 2018). The New York Taxi Workers' Alliance now has some 21,000 members across yellow cabs, taxi-apps and other hire-car services, and keeps up a lively campaign of protests, direct action and legal challenges, directed towards taxi-app companies and regulators alike (NYTWA 2020). Unions elsewhere have similarly sought to organise and represent platform workers, especially those involved in driving, delivery and courier work, and have often used legal and regulatory means to do so.

This brief survey of evidence is by no means intended to claim that unions have in any sense overcome the challenge posed by platforms and platform management methods. However, as the Financial Times pointed out in 2016, the market advantage of companies such as Uber largely rested on the avoidance of standard business regulation; that is, the strategy of 'legal and regulatory arbitrage' (Kaminska 2016). However, as the FT warned at the time, these advantages would run out to the extent that drivers became organised and authorities began to re-regulate taxi-apps as transport. In many parts of the world, this has begun to happen in relatively significant ways. For the present argument, then, these developments represent another aspect of platform management methods where control and resistance are jointly present.

\section{DISCUSSION AND CONCLUSIONS}

The contribution of this chapter is to demonstrate that patterns of platform worker resistance are linked to platform management methods of control. Theoretically, we have argued that the dual control-resistance dynamic within the labour process means that specific management control measures are likely to generate corresponding patterns of worker resistance. Empirically, despite limitations of space and rather incomplete evidence, we have shown that platform worker resistance has tended to cluster around the three main components of platform management - algorithmic management, pay, and wider regulatory issues - in what might be termed channels of resistance. In addition to channels of resistance (where resistance arises), we can identify three broad forms of resistance (by which it is expressed). First, there are micro-level fiddles and individual resistances, such as eating food during delivery or training algorithms to offer higher pay. This form is also partially collectivised as workers pass around information, whether face to face or, as is often the case, via social media and online forums. Second, we can identify informal 
collective actions - including strikes/log-offs or demonstrations - carried out by groups of platform workers, but without the involvement of unions or other representative organisations. The third form of resistance involves actions organised by unions or other worker representation and advocacy groups, on a more formal basis. These may be collective actions such as strikes/log-offs and demonstrations, but may also include legal action against platforms and campaigns for regulatory reform, which may comprise a mix of individual and collective action. We would view distinctions between different channels and forms of resistance as variations on a continuum rather than as sharply defined typologies. For instance, training the algorithm to offer higher pay could potentially be bracketed with algorithmic management or pay; and distinguishing in practice between types of informal collective and semi-collective action can be tricky. Nevertheless, the two dimensions - channels of resistance and forms of resistance - offer a basic conceptual framework for further research and analysis.

In highlighting the importance of resistance for an adequate understanding of platform work, it is not our intention to suggest that platform control methods are insignificant, or that worker resistance can easily overcome them, the technologies they embed, and the companies that run them. Rather, our argument is that accounts which view platform work narrowly, as a form of control only, are partial and therefore problematic. Platform management is not overthrown but neither does it run without frictions caused by workers' deliberate actions. While evidence remains scarce, what there is suggests that for workers, as Vallas and Schor (2020) put it, platform work is not a cage; at least, no more than many other forms of wage labour at the bottom end of the labour market. As with other methods of labour process control, platform management faces non-trivial levels of worker resistance. As time goes by, workers learn about platform management methods. Workers devise fiddles, figure out which jobs pay best and how to get them, and learn the basics of what rights they have or might claim. As a result, some management imperatives are frustrated, some control measures blunted. Managers adjust their approach, introduce new methods, or modify existing ones, and sometimes make concessions to worker grievances in order to reinforce longer-term objectives. Here, Edwards' (1990) distinction between general control and detailed control is useful: platforms may make concessions on the latter to sustain the former. Accounts of platform work that focus excessively on control miss this wider reality: the dialectic of control and resistance, expressed in patterns of reciprocal (if uneven) influence, each shaping the development of the other (if unevenly), as moments of the dual dynamic of the labour process.

The approach outlined here is compatible with accounts such as Edwards (1989, 1990), Storey (1985) and Hyman (1987), which understand managerial methods as comprising different forms, levels or circuits of control, which exist 
alongside - and sometimes in contradiction with - other managerial strategies and priorities. We have characterised platform work as, inter alia, a system for organising work and managing a workforce, identifying a number of distinct elements (cf. Moore and Joyce 2020). This differentiated account of platform management methods avoids the problematic 'functionalist premises that capital must and can devise coherent systems of control', and any associated 'single-track search for definitive and comprehensive modes of work control' (Storey 1985, p. 194). Contradictions within platform management (Hyman 1987; Storey 1985) are exemplified by the problems that many platforms have encountered in classifying workers as self-employed, while at the same time trying to maintain detailed control over the labour process. This contradiction has led to numerous legal challenges by workers over their employment status. One result has been that platforms have changed parts of their labour control regime in response. Of course, it remains to be seen how exactly these contradictions develop. Broader tensions can be identified between labour process control and other pressing matters that platform managers must deal with: not least, crucial issues of financial management, such as securing sufficient supplies of venture capital and, more fundamentally, actually making a profit. Not only is platform work not a panacea for control of the labour process, but it remains far from clear that platform work offers a viable business model outside a few niche areas.

The framework outlined here could be developed further. Most obviously, the shortage of systematic research on platform worker resistance presents significant obstacles to further theoretical development. Nevertheless, we can point to some potentially useful directions for future research. In particular, there is considerable scope for developing understandings of the different forms of resistance of platform workers, especially micro-level fiddles and resistances, and ways that these may be (partially) collectivised, as well as forms of informally organised collective action. There is also room to develop greater understanding of platform work channels of resistance, exploring, in particular, how these are related to specific methods of labour process control, and how these vary across different platforms and types of platform work. Finally, there is almost no research at all on tensions and contradictions between different aspects of platform work management methods, or between strategies for managing platform work and other aspects of managing a platform (such as financial management, or technology development functions). If we take as our starting point Hyman's (1987, p. 30) insight that different management strategies represent 'different routes to partial failure', the challenge remains to understand how, how far and how fast this process develops for platform work. 


\section{NOTES}

1. We would like to thank the editors for helpful comments and suggestions, and for very great patience. As part of the Digital Futures at Work Research Centre (Digit), this work was supported by the UK Economic and Social Research Council (grant number ES/S012532/1), which is gratefully acknowledged.

2. Although Braverman never expressed it as such.

3. The term 'regulatory arbitrage' refers to the practice whereby companies reduce costs by structuring their business to avoid normal regulatory arrangements. Key examples in platform work include classifying workers as self-employed or independent contractors, thereby avoiding employment and social welfare contributions, and companies that provide transport services classifying themselves as technology firms, thereby avoiding costs associated with transport regulation. For discussion of regulatory arbitrage as a business practice see Fleischer (2010); for applications to platform work see Calo and Rosenblat (2017) and Kaminska (2016).

4. For an alternative list of such everyday resistance see Vallas and Schor (2020, p. 167).

\section{REFERENCES}

Ackroyd, S. and P. Thompson (1999), Organisational Misbehaviour, Sage, London. Agrawal, A., J. Horton, N. Lacetera and E. Lyons (2013), Digitization and the Contract Labor Market: A Research Agenda, w19525, Cambridge, MA, National Bureau of Economic Research, October, accessed at https://doi.org/10.3386/w19525

Ajunwa, I. and D. Greene (2019), 'Chapter 3 Platforms at Work: Automated Hiring Platforms and Other New Intermediaries in the Organization of Work', in S. P. Vallas and A. Kovalainen (eds), Research in the Sociology of Work, Vol. 33, Emerald Publishing Limited, pp. 61-91.

Aslam, Y. and J. Woodcock (2020), 'A History of Uber Organizing in the UK', South Atlantic Quarterly, 119 (2), 412-21.

Attwood-Charles, W. (2019), 'Dimensions of Platform Labor Control and the Experience of Gig Couriers', paper presented at SASE Conference 2019, Fathomless Futures: Algorithmic and Imagined, New York, 27 June.

Bain, P. and P. Taylor (2000), 'Entrapped by the "electronic panopticon"? Worker resistance in the call centre', New Technology, Work and Employment, 15 (1), 2-18.

Berg, J. (2016), Income Security in the On-Demand Economy: Findings and Policy Lessons from a Survey of Crowdworkers, International Labour Office, p. 41.

Berg, J. and H. Johnston (2019), 'Too Good to Be True? A Comment on Hall and Krueger's Analysis of the Labor Market for Uber's Driver-Partners', ILR Review, 72 (1), 39-68.

Berg, J. and U. Rani (2018), Digital Labour Platforms and the Future of Work, Geneva, International Labour Office, p. 160.

Bergvall-Kåreborn, B. and D. Howcroft (2014), 'Amazon Mechanical Turk and the Commodification of Labour: Amazon Mechanical Turk', New Technology, Work and Employment, 29 (3), 213-23.

Beynon, H. (1984), Working for Ford, 2nd edn, Penguin, London.

Borkholder, J., M. Montgomery, M. S. Chen and R. Smith (2018), How Transportation Network Companies Buy, Bully, and Bamboozle Their Way To Deregulation, New 
York, National Employment Law Project and the Partnership for Working Families, p. 39.

Bradshaw, T. (2019), 'Uber loses licence to operate in London', Financial Times, 25 November 2019, accessed at https://www.ft.com/content/78827b06-0f6a-11 ea-a225 $-\mathrm{db} 2 \mathrm{f} 231 \mathrm{cfeae}$ emailId=5ddbaa65eee916000436d737\&segmentId=3d08be62-315f $-7330-5$ bbd-af33dc531acb

Braverman, H. (1974), Labor and Monopoly Capital: The Degradation of Work in the Twentieth Century, Monthly Review Press, New York.

Brown, W. (1962), Piecework Abandoned: The Effect of Wage Incentive Systems on Managerial Authority, Heinemann, London.

Burawoy, M. (1979), Manufacturing Consent: Changes in the Labor Process under Monopoly Capitalism, The University of Chicago Press, Chicago.

Burchill, F. (1976), Introduction to Payment Systems and Pay Structures with a Note on Productivity, Open University Press, Buckingham.

Calo, R. and A. Rosenblat (2017), 'The Taking Economy: Uber, Information, and Power', SSRN Electronic Journal, accessed at https://doi.org/10.2139/ssrn.2929643

Cant, C. (2020), Riding for Deliveroo: Resistance in the New Economy, Polity, Cambridge.

Cant, C. and J. Woodcock (2020), 'Fast Food Shutdown: From Disorganisation to Action in the Service Sector', Capital \& Class, 030981682090635.

Captain, S. (2019), 'Instacart is raising minimum pay again', Fast Company, 6 February 2019, accessed at https://www.fastcompany.com/90303309/instacart-is -raising-minimum-pay-again

Chen, J. Y. (2018), 'Thrown Under the Bus and Outrunning it! The Logic of Didi and Taxi Drivers' Labour and Activism in the On-demand Economy', New Media \& Society, 20 (8), 2691-2711.

Chen, L., A. Mislove and C. Wilson (2015), 'Peeking Beneath the Hood of Uber', in Proceedings of the 2015 ACM Conference on Internet Measurement Conference IMC '15, Tokyo, Japan, ACM Press, pp. 495-508.

Cherry, M. A. (2016), 'Beyond Misclassification: The Digital Transformation of Work', Comparative Labor Law \& Policy Journal, 37 (3), 544-77.

Cherry, M. A. and A. Aloisi (2016), "Dependent Contractors" in the Gig Economy: A Comparative Approach', SSRN Electronic Journal, accessed at https://doi.org/10 $.2139 /$ ssrn. 2847869

Clawson, D. and R. Fantasia (1983), 'Beyond Burawoy: The Dialectics of Conflict and Consent on the Shop Floor', Theory and Society, 12 (5), 671-80.

Conger, K. (2020), 'Uber and Lyft Consider Franchise-Like Model in California', New York Times, 18 August 2020, accessed at https://www.nytimes.com/2020/08/18/ technology/uber-lyft-franchise-california.html

Cruz, K., K. Hardy and T. Sanders (2017), 'False Self-Employment, Autonomy and Regulating for Decent Work: Improving Working Conditions in the UK Stripping Industry', British Journal of Industrial Relations, 55 (2), 274-94.

De Stefano, V. (2015), "The Rise of the "Just-in-Time Workforce": On-Demand Work, Crowd Work and Labour Protection in the "Gig-Economy", SSRN Electronic Journal, accessed at https://doi.org/10.2139/ssrn.2682602

Ditton, J. (1977), Part-time Crime: An Ethnography of Fiddling and Pilferage, Springer, London.

Edwards, P. (1986), Conflict At Work: A Materialist Analysis of Workplace Relations, Basil Blackwell, Oxford. 
Edwards, P. (1989), 'Patterns of Conflict and Accommodation', in D. Gallie (ed.), Employment in Britain, Blackwell, Oxford.

Edwards, P. (1990), 'Understanding Conflict in the Labour Process: The Logic and Autonomy of Struggle', in D. Knights and H. Willmott (eds), Labour Process Theory, Macmillan, Basingstoke, pp. 125-52.

Edwards, P. (1992), 'Industrial Conflict: Themes and Issues in Recent Research', British Journal of Industrial Relations, 30 (3), 361-404.

Edwards, P. (2007), 'The State of the Labour Process Debate after 25 Years: Some Reflections from Industrial Relations and Industrial Sociology', in Notes for Remarks to Plenary Panel at the 25th International Labour Process Conference, Amsterdam, April 2007, accessed at https://warwick.ac.uk/fac/soc/wbs/research/ irru/publications/recentconf/pe lpc07.pdf

Edwards, R. (1979), Contested Terrain: The Transformation of the Workplace in the Twentieth Century, Heinemann, London.

Farrell, D. and F. Greig (2016), Paychecks, Paydays, and the Online Platform Economy, JPMorgan Chase \& Co. Institute, Washington DC.

Fine, B. and A. Saad Filho (2010), Marx's Capital, 4th edn, Pluto Press, London.

Fleischer, V. (2010), 'Regulatory Arbitrage', Texas Law Review, 89, 227-75.

Florisson, R. and I. Mandl (2018), Platform Work: Types and Implications for Work and Employment - Literature Review, Eurofound, Dublin.

Forde, C., M. Stuart, S. Joyce, L. Oliver, D. Valizade, G. Alberti, K. Hardy, V. Trappmann, C. Umney and C. Carson (2017), The Social Protection of Workers in the Platform Economy, EMPL committee of the European parliament, D-G Internal Policies, European Commission, Brussels.

Friedman, A. L. (1977), Industry and Labour: Class Struggle at Work and Monopoly Capitalism, Vol. 82, Macmillan, London.

Gandini, A. (2019), 'Labour Process Theory and the Gig Economy', Human Relations, 72 (6), 1039-56.

Ghaffary, S. (2019), 'DoorDash is still pocketing workers' tips, almost a month after it promised to stop', Vox Recode, 20 August 2019, accessed at https://www.vox .com/recode/2019/8/20/20825937/doordash-tipping-policy-still-not-changed-food -delivery-app-gig-economy

Gilbert, B. (2019), 'Almost 30\% of delivery drivers admit to taking food from an order, according to a new survey', Business Insider, 31 July 2019, accessed at https://www .businessinsider.com/uber-eats-delivery-drivers-eating-food-2019-7? $\mathrm{r}=\mathrm{US} \& \mathrm{IR}=\mathrm{T}$

Griesbach, K., A. Reich, L. Elliott-Negri and R. Milkman (2019), 'Algorithmic Control in Platform Food Delivery Work', Socius: Sociological Research for a Dynamic World, 5, 237802311987004.

Hall, J. V. and A. B. Krueger (2018), 'An Analysis of the Labor Market for Uber's Driver-Partners in the United States', ILR Review, 71 (3), 705-32.

Hall, J. V., J. J. Horton and D. T. Knoepfle (2019), 'Pricing Efficiently in Designed Markets: The Case of Ride-Sharing', Semantic Scholar, p. 76, accessed at https:// www.semanticscholar.org/paper/Pricing-Efficiently-in-Designed-Markets\%3A-The -Case-Hall-Horton/c96ad4e51587c3d7ed900f7a90da1d2dd86337bb

Harris, S. D. and A. B. Krueger (2015), A Proposal for Modernizing Labor Laws for Twenty-First-Century Work: The "Independent Worker", Discussion Paper 2015-10, Brookings, Washington, DC.

Hill, S. (1976), The Dockers: Class and Tradition in London, Heinemann Educational Books, London. 
Horton, J. J. and R. J. Zeckhauser (2016), Owning, Using and Renting: Some Simple Economics of the "Sharing Economy", No. w22029, National Bureau of Economic Research, p. 42.

Howcroft, D. and B. Bergvall-Kåreborn (2019), 'A Typology of Crowdwork Platforms', Work, Employment and Society, 33 (1), 21-38.

Huws, U., N. H. Spencer, D. S. Syrdal and K. Holts (2017), Work in the European Gig Economy: Research Results from the UK, Sweden, Germany, Austria, The Netherlands, Switzerland and Italy, FEPS and Uni-Europa, Brussels.

Hyman, R. (1975), Industrial Relations: A Marxist Introduction, Macmillan, London.

Hyman, R. (1987), 'Strategy or Structure? Capital, Labour and Control', Work, Employment \& Society, 1 (1), 25-55.

Irani, L. (2015), 'Difference and Dependence among Digital Workers: The Case of Amazon Mechanical Turk', South Atlantic Quarterly, 114 (1), 225-34.

Irani, L. C. and S. Silberman (2013), 'Turkopticon: Interrupting Worker Invisibility in Amazon Mechanical Turk', in Proceedings of the SIGCHI Conference on Human Factors in Computing Systems - CHI '13, Paris, France, ACM Press, p. 611.

Ivanova, M., J. Bronowicka, E. Kocher and A. Degner (2018), 'The App as a Boss? Control and Autonomy in Application-Based Management', Arbeit | Grenze | Fluss - Work in Progress Interdisziplinärer Arbeitsforschung, accessed at https://doi.org/ 10.11584/ARBEIT-GRENZE-FLUSS.2

Johnston, H. and C. Land-Kazlauskas (2018), Organizing On-Demand: Representation, Voice, and Collective Bargaining in the Gig Economy, 94, Geneva, International Labour Office, p. 54.

Joyce, S. (2020), 'Rediscovering the Cash Nexus, Again: Subsumption and the LabourCapital Relation in Platform Work', Capital \& Class, March 2020. doi:10.1177/ 0309816820906356

Joyce, S., D. Neumann, V. Trappmann et al. (2020), A Global Struggle: Worker Protest in the Platform Economy, ETUI Policy Brief, 2/2020, ETUI, Brussels.

Kaminska, I. (2016), 'Mythbusting Uber's valuation', FT Alphaville, Financial Times, 13 September 2016.

Kenney, M. and J. Zysman (2016), 'The Rise of the Platform Economy', Issues in Science and Technology, 32 (3), 61-9.

Khan, M. and A. Ram (2017), 'ECJ rules Uber can be regulated as taxi company', Financial Times, 20 December 2017.

Kokkodis, M. and P. G. Ipeirotis (2016), 'Reputation Transferability in Online Labor Markets', Management Science, 62 (6), 1687-1706.

Lazonick, W. (1979), 'Industrial Relations and Technical Change: The Case of the Self-acting Mule', Cambridge Journal of Economics, 3 (3), 231-62.

Lehdonvirta, V., O. Kässi, I. Hjorth, H. Barnard and M. Graham (2019), 'The Global Platform Economy: A New Offshoring Institution Enabling Emerging-Economy Microproviders', Journal of Management, 45 (2), 567-99.

Littler, C. R. (1982), The Development of the Labour Process in Capitalist Societies: A Comparative Study of the Transformation of Work Organization in Britain, Japan, and the USA, Heinemann Educational Publishers, London.

Mars, G. (1982), Cheats at Work: An Anthropology of Workplace Crime, George Allen and Unwin, London.

Marx, K. (1976), Capital: A Critique of Political Economy, Vol.1, Penguin, London.

McCulloch, A. (2019), 'Deliveroo and Uber Eats face questions over worker black market', Personnel Today, 7 January 2019, accessed at https://www.personneltoday .com/hr/deliveroo-and-uber-eats-face-black-market-worker-questions/ 
Moody, K. (2018), On New Terrain, Haymarket, Chicago.

Moore, D. P. V. (2018), The Threat of Physical and Psychosocial Violence and Harassment in Digitalized Work, International Labour Office, p. 54.

Moore, P. V. and S. Joyce (2020), 'Black Box or Hidden Abode? The Expansion and Exposure of Platform Work Managerialism', Review of International Political Economy, 27 (4), 1-23.

NYTWA (2020), New York Taxi Workers' Alliance, http://www.nytwa.org/

Parrott, J. and M. Reich (2018), ‘An Earnings Standard for New York City's App-based Drivers: Economic Analysis and Policy Assessment', Report for the New York City Taxi and Limousine Commission, Center for New York City Affairs, New School, New York.

Park, J. (2021), 'Court rules California gig worker initiative is unconstitutional, a setback to Uber and Lyft', Sacremento Bee, 20 August 2021, accessed at https:// www.sacbee.com/news/politics-government/capitol-alert/article253647838.html \#storylink=cpy

Raval, N. and P. Dourish (2016), 'Standing Out from the Crowd: Emotional Labor, Body Labor, and Temporal Labor in Ridesharing', in Proceedings of the 19th ACM Conference on Computer-Supported Cooperative Work \& Social Computing CSCW '16, San Francisco, California, ACM Press, pp. 97-107.

Ravenelle, A. J. (2017), 'Sharing Economy Workers: Selling, not Sharing', Cambridge Journal of Regions, Economy and Society, 10 (2), 281-95.

Rosenblat, A. and L. Stark (2016), 'Algorithmic Labor and Information Asymmetries: A Case Study of Uber's Drivers', International Journal of Communication, 10, 3758-84.

Salehi, N., L. C. Irani, M. S. Bernstein, A. Alkhatib, E. Ogbe, K. Milland and Clickhappier (2015), 'We Are Dynamo: Overcoming Stalling and Friction in Collective Action for Crowd Workers', in Proceedings of the 33rd Annual ACM Conference on Human Factors in Computing Systems - CHI '15, Seoul, Republic of Korea, ACM Press, pp. 1621-30.

Samuel, R. (1977), 'Workshop of the World: Steam Power and Hand Technoloy in Mid-Victorian Britain', History Workshop Journal, 3 (1), 6-72.

Schloss, D. F. (1898), Methods of Industrial Remuneration, Williams and Norgate, London.

Schmidt, F. A. (2017), Digital Labour Markets in the Platform Economy, Friedrich-Ebert-Stiftung, p. 32.

Schörpf, P., J. Flecker, A. Schönauer and H. Eichmann (2017), 'Triangular Love-Hate: Management and Control in Creative Crowdworking', New Technology, Work and Employment, 32 (1), 43-58.

Shapiro, A. (2018), 'Between Autonomy and Control: Strategies of Arbitrage in the “On-demand" Economy', New Media \& Society, 20 (8), 2954-71.

Sharma, P. (2020), 'Digitalisation and Precarious Work Practices in Alternative Economies: Work Organisation and Work Relations in E-cab Services', Economic and Industrial Democracy, 0143831X2092446.

Srnicek, N. (2016), Platform Capitalism, Polity Press, Cambridge.

Stanford, J. (2017), 'The Resurgence of Gig Work: Historical and Theoretical Perspectives', Economic and Labour Relations Review, 28 (3), 382-401.

Storey, J. (1985), 'The Means of Management Control', Sociology, 19 (2), 193-211.

Tassinari, A. and V. Maccarrone (2020), 'Riders on the Storm: Workplace Solidarity among Gig Economy Couriers in Italy and the UK', Work, Employment and Society, 34(1), 35-54. 
Thompson, P. (1990), 'Crawling from the Wreckage: The Labour Process and the Politics of Production', in D. Knights and H. Willmott (eds), Labour Process Theory, Macmillan, Basingstoke, pp. 95-124.

Thompson, P. and C. Smith (2010), 'Debating Labour Process Theory and the Sociology of Work', in P. Thompson and C. Smith (eds), Working Life: Renewing Labour Process Analysis, Palgrave Macmillan, Basingstoke, pp. 11-28.

Vallas, S. and J. B. Schor (2020), 'What do Platforms Do? Understanding the Gig Economy', Annual Review of Sociology, 46, 273-94.

van Doorn, N. and A. Badger (2020), 'Platform Capitalism's Hidden Abode: Producing Data Assets in the Gig Economy', Antipode, anti.12641.

Veen, A., T. Barratt and C. Goods (2020), 'Platform-Capital's "App-etite" for Control: A Labour Process Analysis of Food-Delivery Work in Australia', Work, Employment \& Society, 34 (3), 388-406.

Webb, S. and B. Webb (1902), Industrial Democracy, Longman, London.

Wood, A. J., M. Graham, V. Lehdonvirta and I. Hjorth (2018), 'Good Gig, Bad Gig: Autonomy and Algorithmic Control in the Global Gig Economy', Work, Employment and Society, 33 (1), 56-75.

Woodcock, J. (2018), 'Digital Labour and Workers' Organisation', in M. Atzeni and I. Ness (eds), Global Perspectives on Workers' and Labour Organizations, Springer, Singapore.

Woodcock, J. (2020), 'The Algorithmic Panopticon at Deliveroo: Measurement, Precarity, and the Illusion of Control', Ephemera, 21.

Woodcock, J. and M. R. Johnson (2018), 'Gamification: What It Is, and How to Fight It', The Sociological Review, 66 (3), 542-58.

Wu, Q., H. Zhang, Z. Li and K. Liu (2019), 'Labor Control in the Gig Economy: Evidence from Uber in China', Journal of Industrial Relations, 61 (4), 574-96. 